\title{
Qualidade de frutos de híbridos de melancia com sementes
}

\author{
de Oliveira, Milena Maria Tomaz ${ }^{1,5}$; Ricardo Elesbão Alves²; Leirson Rodrigues da \\ Silva $^{3}$; Fernando Antonio Souza de Aragão ${ }^{4}$
}

${ }^{1}$ Ben-Gurion University of the Negev, The French Associates Institute for Agriculture and Biotechnology of Drylands, Midreshet Ben-Gurion, 84990, Israel; ${ }^{2}$ Embrapa Alimentos e Territórios, Rua Buarque de Macêdo, Maceió-AL, Brasil; ${ }^{3}$ Fitotecnia, Departamento de Ciências Vegetais, UFERSA-RN; ${ }^{4}$ Empresa Brasileira de Pesquisa Agropecuária, Centro Nacional de Pesquisa de Agroindústria Tropical, Fortaleza, CE; ${ }^{5}$ phdmilenaoliveira@gmail.com

de Oliveira, Milena Maria Tomaz; Ricardo Elesbão Alves; Leirson Rodrigues da Silva; Fernando Antonio Souza de Aragão (2019) Qualidade de frutos de híbridos de melancia com sementes. Rev. Fac. Agron. Vol 118 (1): 77-83.

\begin{abstract}
O presente trabalho objetivou avaliar a qualidade pós-colheita de dois híbridos de melancia com sementes cultivadas sob manejo convencional. As características de qualidade analisadas foram: massa fresca; diâmetro longitudinal e transversal; índice de formato do fruto (IF: DL/DT); espessura da casca; firmeza da polpa; sólidos solúveis; acidez titulável; pH; SS/AT; açúcares solúveis totais e redutores; pectina solúvel; vitamina C; carotenoides totais; licopeno; flavonoides; antocianinas e polifenóis extraíveis totais. O ensaio em condições laboratoriais foi estabelecido em delineamento inteiramente casualizado (DIC). Os resultados foram submetidos à análise de variância (ANOVA). Os híbridos apresentaram massa fresca, DL/DT, cor, sólidos solúveis, acidez titulável e SS/AT satisfatórios para comercialização; com destaque para o híbrido 'Boston' que apresentou maior teor de sólidos solúveis (9.90 ํix), açúcares solúveis totais (6.66 \%) e SS/AT (86.24). Para compostos bioativos, o híbrido 'Boston' apresentou valores médios superiores para carotenoides totais (2.03 mg 100g-1) e flavonoides amarelos (3.21 mg 100g-1), entretanto, o híbrido 'Quetzali' obteve destaque para os polifenóis extraíveis totais (194.36 mg 100g-1), podendo, desta forma, ser usados na promoção da saúde humana. Embora os híbridos avaliados tenham se mostrado qualitativamente favoráveis ao consumo, tenham se mostrado qualitativamente favoráveis ao consumo, os resultados aqui encontrados indicam estreitamento da base genética, o que torna necessário a avaliação de outros híbridos
\end{abstract}

Palavras-chave: Citrullus lanatus, cultivares comerciais, pós-colheita, sólidos solúveis, flavonoides amarelos, polifenóis extraíveis totais.

de Oliveira, Milena Maria Tomaz; Ricardo Elesbão Alves; Leirson Rodrigues da Silva; Fernando Antonio Souza de Aragão (2019) Fruit quality of watermelon hybrids with seeds. Rev. Fac. Agron. Vol 118 (1): 7783.
This investigation was aimed to evaluate the quality postharvest of two seeds watermelon hybrids grown under conventional management. The quality characteristics analyzed were: fresh mass; longitudinal and transverse diameter; fruit format index (IF: DL/DT); shell thickness; pulp firmness; soluble solids; titratable acidity; $\mathrm{pH}$; SS/TA ratio; total soluble and reducing sugars; soluble pectin; vitamin $\mathrm{C}$; total carotenoids; lycopene; yellow flavonoids; anthocyanins and total extractable polyphenols. A completely randomized design (CRD) was carried out. The results were submitted to analysis of variance (ANOVA). Those hybrids showed fresh mass, DL/DT, color, soluble solids, titratable acidity and SS/TA satisfactory for commercialization; with emphasis on the 'Boston' hybrid which showed higher soluble solids content $\left(9.90^{\circ}\right.$ Brix), total soluble sugars $(6.66 \%)$ and SS/TA (86.24). For bioactive compounds, 'Boston' hybrid had higher mean values for total

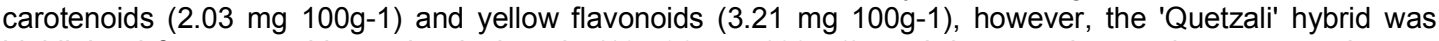 highlighted for extractable total polyphenols (194.36 mg 100g-1), and thus can be used to promote human health. Although the hybrids tested have shown to be qualitatively favorable to consumption, these results indicate a narrowing of the genetic base, which makes it necessary the evaluation of other watermelon seeds hybrids.

Keywords: Citrullus lanatus, commercial cultivars, postharvest, total soluble sugars, yellow flavonoids, total extractable polyphenols.

https://doi.org/10.24215/16699513e008
https://revistas.unlp.edu.ar/revagro
Recibido: 26/12/2015
Aceptado: $18 / 02 / 2019$
Disponible on line: 01/07/2019
ISSN 0041-8676 - ISSN (on line) 1669-9513, Facultad de Ciencias Agrarias y Forestales, UNLP, Argentina 


\section{INTRODUÇÃO}

A melancia [Citrullus lanatus (Thunb.) Matsum e Nakai] é uma olerácea pertencente à família Cucurbitaceae, originária da África e de grande importância econômica no mundo e no Brasil, principalmente na região Nordeste. Mundialmente tem sido cultivada em países como China, Irã e Turquia, que responderam por mais de $77 \%$ da produção mundial (FAO, 2011). No cenário nacional, a cultura destaca-se como a quarta hortaliça de maior importância, com uma produção de 2,1 milhões de toneladas de frutos em uma área de 98,5 mil hectares e destes, 35,8 mil encontram-se na região Nordeste, aonde seu cultivo vem sendo realizado em pequenas, médias e grandes áreas, predominantemente em unidades de agricultura familiar (IBGE, 2006).

As plantas são herbáceas, anuais, de caule sarmentoso com folhas geralmente lobadas. Seus frutos são utilizados principalmente na forma in natura, sendo muitas vezes apreciados pelo seu sabor adocicado e refrescante, especialmente nas horas mais quentes do dia. A casca pode ser aproveitada para a fabricação de doces, dentre outros produtos (SANTANA; OLIVEIRA, 2005) e em algumas regiões as sementes são consumidas tostadas. No mercado americano, por exemplo, a melancia é comercializada em fatias com casca ou na forma de cubos sem casca (PERKINS-VEAZIE; COLLINS, 2004) e esta prática já é uma tendência no Brasil. Além disso, o fruto é rico em uma gama de constituintes químicos, onde se destaca principalmente o licopeno (pigmento avermelhado), $\beta$ caroteno (pigmento amarelado) e carotenoides totais que, segundo Gomes (2007), são fontes potenciais de antioxidantes naturais, tendo como função inibir ou retardar a ação de radicais livres no organismo humano, contribuindo assim para minimizar a ocorrência e desenvolvimento de doenças cancerígenas e/ou degenerativas.

É importante ressaltar que a região Nordeste se caracteriza como um pólo promissor no cultivo de variedades comerciais de melancia, onde podemos citar principalmente os Estados do Ceará e Rio Grande do Norte, como mercados destinados a expansão do produto no agronegócio brasileiro e apresentando-se com expressiva relevância socioeconômica para o país. Nestes locais, o sistema de cultivo das espécies de melancia é crescente, sobretudo, no Agropolo Jaguaribe-Açu, região que apresenta condições satisfatórias de clima e solo, favoráveis ao cultivo intensivo de produtos hortifrutícolas de qualidade destinados à exportação (GOMES, 2010).

As cultivares de melancia tradicionalmente disponíveis no mercado são muitas e, dentre os fatores genéticos, a seleção de cultivares é de importância primária para a obtenção de produtos resistentes ao transporte e com melhor aparência. Estas cultivares não só variam em forma, tamanho, cor, teor de sólidos solúveis, acidez titulável e compostos com propriedades funcionais, como tambémem sua capacidade para atingir o fenótipo desejado quando submetidas a diferentes condições de produção (CHITARRA; CHITARRA, 2005).

A caracterização e avaliação da variabilidade genética constituem ferramentas indispensáveis aos trabalhos ligados ao melhoramento de plantas (CAVALCANTE; LIRA, 2010), todavia, há poucos trabalhos na literatura que comparem a qualidade dos frutos de diferentes híbridos de melancia, no que diz respeito à caracterização física, físico-química e de compostos bioativos.

Apesar de informações a respeito da caracterização bromatológica das mais diversas variedades serem divulgadas pelas empresas de sementes, essas são, em geral, genéricas e não traduzem necessariamente o comportamento dos híbridos em determinadas condições ambientais. Dessa forma, o presente trabalho objetivou avaliar a qualidade pós-colheita de dois híbridos de melancia com sementes ('Boston' e 'Quetzali'), cultivados sob manejo convencional nas condições edafoclimáticas dos Estados do Ceará e Rio Grande do Norte.

\section{MATERIAL E MÉTODOS}

Os frutos de melancia foram coletados em fazendas comerciais localizadas no polo agrícola JaguaribeAçu nas cidades de Mossoró (Latitude: -5.18804, Longitude: $-37.3441 ; 5^{\circ} 11^{\prime} 17^{\prime \prime}$ Sul, $\left.37^{\circ} 20^{\prime} 39^{\prime \prime}\right)$, que apresenta clima tropical com estação seca, mediante classificação climática de Köppen-Geiger: As) e está situada na mesorregião oeste potiguar no Estado do Rio Grande do Norte; Quixeré (Latitude: -5.0778, Longitude: -37.9854; $5^{\circ} 4^{\prime} 40^{\prime \prime}$ Sul, $\left.37^{\circ} 59^{\prime} 7^{\prime \prime}\right)$, esta apresentando clima tropical com estação seca, mediante classificação climática de Köppen-Geiger: As) e situada na mesorregião do Jaguaribe no Estado do Ceará, estes colhidos durante a safra 2009/2010.

Os híbridos avaliados foram: 'Boston' e 'Quetzali' (com sementes). Os frutos foram colhidos em estádio de maturação comercial (maduro), nas primeiras horas do dia, por coletores treinados. Em seguida, foram selecionados, embalados em caixas de papelão abertas tipo peça únicos e encaminhados à Embrapa Agroindústria Tropical em Fortaleza-CE, onde foram recepcionados e armazenados temporariamente em câmara fria a $10 \pm 2{ }^{\circ} \mathrm{C}$.

Para as avaliações físicas foram tomados quinze frutos e realizadas mensurações individuais para cada fruto dos híbridos estudados. Em seguida, os frutos foram divididos em três porções (cinco frutos por repetição), processados em multiprocessador WALITA $®$ para posterior realização das análises físicas, físico-químicas e de compostos bioativos, como segue:

Características físicas: massa fresca dos frutos $(\mathrm{g})$ : obtido mediante leitura direta em balança semianalitica; Dimensões e índice de formato do fruto (cm): diâmetro longitudinal, diâmetro transversal e espessura da casca (casca + polpa branca) (região medial), foram determinados com o auxílio de uma régua milimetrada, realizando-se uma leitura para cada metade do fruto. $O$ índice de formato do fruto foi estabelecido a partir da razão entre diâmetro longitudinal e transversal; Firmeza da polpa (N): com o auxílio de um penetrômetro manual Magness-Taylor modelo FT $011 \mathrm{com}$ ponteira de $12 \mathrm{~mm}$ de diâmetro. Foram realizadas três leituras em lados opostos da porção equatorial de cada fruto, obtendo-se a média e coloração da polpa: medida por reflectância utilizando-se um colorímetro da marca MINOLTA (Modelo Chroma Meter CR-200B), no padrão C. I. E (CommissionInternacionale de L'Eclaraige), realizando-se duas medições em pontos equidistantes da região mediana de cada fruto. Foi considerada a média aritmética das medidas. Para a 
caracterização objetiva da cor usou-se o sistema CIELAB $\left(L^{*} a^{*} b^{*}\right)$ (MCGUIRE, 1992).

Características físico-químicas: sólidos solúveis: determinado com o auxílio de um refratômetro digital da marca ATAGO PR-101 (0 a $45^{\circ}$ Brix) (AOAC, 2000); Acidez titulável (AT): determinada em percentagem de ácido cítrico (IAL, 2005), com modificações quanto à titulação, sendo a mesma efetuada pelo procedimento eletrométrico comsolução de $\mathrm{NaOH} 0,1 \mathrm{~N}$ até $\mathrm{pH} \pm 8,2$; SS/AT: obtida mediante $\mathrm{O}$ quociente entre as duas características; $\mathrm{pH}$ : determinado com o auxílio de um potenciômetro digital (Mettler DL 12) com membrana de vidro, calibrado com tampões de $\mathrm{pH} 4$ e 7 de acordo com AOAC (2000); Açúcares solúveis totais: determinados pelo método da Antrona, segundo Yemn e Willis (1954), com modificações e teores médios expressos em percentagem; Açúcares redutores: determinados pelo método do DNS, segundo Miller (1959), com modificações e teores médios expressos em percentagem; Pectina solúvel: determinado pelo método do $\mathrm{m}$-hidroxidifenil segundo metodologia descrita por Mccready e McComb (1952), com modificações e os resultados expressos em percentagem.

Compostos bioativos: Vitamina C (mg $\left.100 \mathrm{~g}^{-1}\right)$ : determinado de acordo com Strohecker e Henning (1967), com modificações quanto à diluição (10 g de amostra diluídas em $100 \mathrm{~mL}$ de ácido oxálico 0,5\%); Antocianinas e flavonoides amarelos (mg $\left.100 \mathrm{~g}^{-1}\right)$ : segundo Francis (1982); Carotenoides totais(mg 100 $\left.\mathrm{g}^{-1}\right)$ : determinados pelo método de Higby (1962), com modificações; Polifenóis extraíveis totais $\left(\mathrm{mg} 100 \mathrm{~g}^{-1}\right)$ : segundo Larrauri et al. (1997) com modificações e Licopeno $\left(\mathrm{mg} 100 \mathrm{~g}^{-1}\right.$ ): de acordo com RodriguezAmaya (2001), com modificações.

O ensaio em condições laboratoriais foi estabelecido em delineamento inteiramente casualizado (DIC). As análises de variância foram realizadas pelo software SISVAR (FERREIRA, 2005). Realizou-se a ANOVA e adotou-se o teste de Tukey a $5 \%$ de probabilidade para a comparação entre as médias dos híbridos.

\section{RESULTADOS E DISCUSSÃO}

A caracterização física de frutos dos diferentes híbridos de melancia avaliados encontra-se na Tabela 1. Observou-se maior massa média de frutos para o híbrido 'Quetzali', valor este de $3630.26 \mathrm{~g}$.

De maneira geral, os dois híbridos avaliados apresentam frutos considerados pequenos, com massa média dos frutos inferior a $6 \mathrm{~kg}$. No mercado brasileiro, observa-se uma valorização por frutos com massa acima de $6 \mathrm{~kg}$, padrão 'Crimson Sweet'. No entanto, vale salientar que devido à redução no tamanho das famílias, há uma demanda crescente por frutos menores (abaixo de $6 \mathrm{~kg}$ ) (DIAS; LIMA, 2010), que facilitam o consumo e evitam o desperdício, como é o caso dos híbridos estudados neste trabalho.

O híbrido 'Quetzali' apresentou os maiores diâmetros longitudinal e transversal, com valores de 19.84 e $18.63 \mathrm{~cm}$, respectivamente. Houve pouca variação quanto aos índices médios de formato do fruto. Pela relação DL/DT, verifica-se que estes estão acima de 1 , o que dá a confirmação que todos os híbridos avaliados são esféricos e desta forma, apresentam maior porção de polpa comestível e vantagens quanto à acomodação em caixas para o transporte, principalmente neste caso, onde os frutos são considerados pequenos (massa média inferior a 6 $\mathrm{kg}$ ). Esta conformação é semelhante à encontrada por Barros et al. (2012) que verificaram índice médio de formato do fruto de 1,07 o que, de forma geral, significa que os frutos apresentam formato do fruto próximo ao esférico.

Os híbridos não diferiram entre si quanto à espessura média de casca (casca + polpa branca), tendo 'Quetzali' apresentado o maior valor médio, $1.08 \mathrm{~cm}$ e 'Boston' o menor, $1.06 \mathrm{~cm}$, o que confere menor resistência pós-colheita e requer maiores cuidados no manuseio e transporte. De acordo com Silva et al. (2008), a espessura de casca está relacionada com a resistência da mesma. Isso porque o sistema de produção da melancia é predominantemente feito a granel, exigindo uma espessura de casca que suporte a manipulação dos frutos.

Pela firmeza da polpa, os resultados mostram que o híbrido 'Boston' obteve o maior valor médio (12.21 N). Este fato evidencia sua maior resistência às injúrias mecânicas sofridas devido ao transporte além de uma maior vida útil pós-colheita se comparado ao híbrido 'Quetzali' que obteve o menor valor médio para esta característica (12.02 N) (Tabela 1).

Os resultados obtidos na análise colorimétrica de frutos dos híbridos de melancia cultivados encontramse na tabela 2. Todos os híbridos analisados apresentaram valores médios de luminosidade $\left(\mathrm{L}^{*}\right)$ inferiores a 50. Como a escala varia a 0 (indica cores escuras e opacas) a 100 (cores brancas ou de brilho máximo), pode-se dizer que estes frutos apresentamse mais para opacos, que brilhantes.

Tabela 1. Características físicas de frutos de diferentes híbridos de melancia cultivados nas condições edafoclimáticas dos Estados do Ceará e Rio Grande do Norte. Referencias: Média \pm Desvio padrão; C.V. = Coeficiente de variação. ${ }^{1} \mathrm{MF}=$ Massa fresca; ${ }^{2} D L=$ Diâmetro longitudinal; ${ }^{3} D T=$ Diâmetro transversal; ${ }^{4} I F=$ Índice de formato $(D L / D T) ;{ }^{5} E C=$ Espessura da casca; ${ }^{6} \mathrm{~F}=$ Firmeza da polpa. Médias seguidas por pelo menos mesma letra nas colunas não diferem entre si, pelo teste de Tukey, ao nível de $5 \%$ de probabilidade.

\begin{tabular}{lcccccc}
\hline \multirow{2}{*}{ Híbridos } & $\mathbf{M F}^{1}(\mathbf{g})$ & $\mathbf{D L}^{2}(\mathbf{c m})$ & $\mathbf{D T}^{3}(\mathbf{c m})$ & $\mathbf{I F}^{4}$ & $\mathbf{E C}^{5}(\mathbf{c m})$ & $\mathbf{F}^{\mathbf{6}}(\mathbf{N})$ \\
\cline { 2 - 7 } & $2567.73 \pm 236.56^{\mathrm{b}}$ & $17.59 \pm 0.64^{\mathrm{b}}$ & $17.17 \pm 0.62^{\mathrm{b}}$ & $1.02 \pm 0.04^{\mathrm{b}}$ & $1.06 \pm 0.22^{\mathrm{a}}$ & $12.21 \pm 2.20^{\mathrm{a}}$ \\
Boston & $3630.26 \pm 521.09^{\mathrm{a}}$ & $19.84 \pm 1.11^{\mathrm{a}}$ & $18.63 \pm 0.89^{\mathrm{a}}$ & $1.06 \pm 0.03^{\mathrm{a}}$ & $1.08 \pm 0.23^{\mathrm{a}}$ & $12.02 \pm 0.98^{\mathrm{a}}$ \\
\hline Quetzali & 3099.30 & 18.71 & 17.90 & 1.04 & 1.07 & 12.12 \\
\hline Média geral & 13.06 & 4.83 & 4.28 & 3.24 & 27.14 & 14.08 \\
\hline
\end{tabular}


Tabela 2. Resultados da análise colorimétrica de frutos dos híbridos de melancia cultivados nas condições edafoclimáticas dos Estados do Ceará e Rio Grande do Norte, de acordo com o sistema CIELAB (L*a*b*). Referencias: Média \pm Desvio padrão; C.V. $=$ Coeficiente de variação. ${ }^{1} L^{*}=$ Claridade; ${ }^{2} a^{*}=$ Componentes verdevermelho; ${ }^{3} b^{*}=$ Componentes azul-amarelo; ${ }^{4} \mathrm{Hue}=$ Tonalidade cromática correspondente ao ângulo Hue. Médias seguidas por pelo menos mesma letra nas colunas não diferem entre si, pelo teste de Tukey, ao nível de 5\% de

\begin{tabular}{lcccc}
\hline \multirow{2}{*}{ Híbridos } & \multicolumn{4}{c}{ Parâmetros CIELAB } \\
\cline { 2 - 5 } & $\mathbf{L}^{*}$ & $\mathbf{a}^{*}$ & $\mathbf{b}^{*}$ & ${ }^{\circ}$ Hue \\
\hline Boston & $39.54 \pm 3.72^{\mathrm{a}}$ & $16.42 \pm 3.18^{\mathrm{b}}$ & $8.22 \pm 1.56^{\mathrm{b}}$ & $26.94 \pm 4.62^{\mathrm{a}}$ \\
Quetzali & $41.10 \pm 2.44^{\mathrm{a}}$ & $22.62 \pm 2.40^{\mathrm{a}}$ & $19.59 \pm 2.20^{\mathrm{a}}$ & $24.79 \pm 3.13^{\mathrm{a}}$ \\
\hline Média geral & 40.32 & 19.52 & 9.41 & 25.87 \\
\hline CV (\%) & 7.79 & 14.93 & 21.04 & 15.82 \\
\hline
\end{tabular}

Este fato justifica a coloração vermelho intenso da polpa, e desta forma, todos os híbridos apresentam aspectos relevantes quanto à aparência. O máximo valor médio para o componente $\mathrm{L}^{*}$ (grau de brilho) obtido entre os híbridos foi de 41.10 para 'Quetzali'. Resultados semelhantes foram encontrados por Teixeira et al. (2011) ao trabalhar com qualidade de genótipos de melancia encontraram resultados inferiores: 'Sugar Baby' com 25.28 e 'Smile'com 13.91 de menor luminosidade.

Com relação ao índice $a^{*} e b^{*}$, houve diferença significativa entre os tratamentos. Para o índice $b^{*}, 0$ híbrido 'Quetzali' apresentou maior intensidade de cor amarela. Pode-se observar que 0 índice $a^{*}$ apresentou valores maiores que 0 índice $b^{*}$, demonstrando maior intensidade de cor vermelha, uma característica positiva para o fruto de melancia, já que hoje o mercado busca frutos com coloração, mais atrativa ao consumidor. Para o ângulo Hue, o híbrido 'Boston' apresentou o maior valor.

As características físico-químicas de frutos de diferentes híbridos de melancia encontram-se na tabela 3. Não foi observada variação nos teores médios de sólidos solúveis de $9.28{ }^{\circ}$ Brix para o híbrido 'Quetzali' e 9.90 `Brix para 'Boston'.

Resultados semelhantes foram encontrados por Teixeira et al. (2011) que, trabalhando com híbridos de melancia 'Smile e 'Sugar Baby' na Embrapa Semiárido, encontraram teores de sólidos solúveis variando entre 8.55 e $11.80^{\circ}$ Brix obtidos na região central da polpa. Por outro lado, Araújo Neto et al. (2010) avaliando a vida útil pós-colheita da variedade 'Crimson Sweet', produzida na região de Mossoró, $\mathrm{RN}$, mostram que o conteúdo de sólidos solúveis encontrado variou de 7.63 a $9.55{ }^{\circ}$ Brix, valores inferiores aos encontrados neste trabalho. Cabe ressaltar ainda que por ser uma característica de relevante importância, a mesma é muito influenciada por fatores do meio, entre os quais se destacam o genótipo, local de plantio e condução da cultura (DESWAL; PATIL, 1984) e deste modo, devido aos híbridos terem sido cultivados sob ótimas condições de manejo em fazendas comerciais destinadas à exportação, os mesmos, de maneira geral, apresentaram resultados condizentes com as exigências de mercado, que é de 11 a $13^{\circ}$ Brix para melancia, intervalo aceitável para os híbridos que mais se destacam comercialmente (SILVA, 2010).

Para a acidez total titulável, observou-se variação entre os híbridos analisados de 0.11 para 'Boston' e $0.14 \%$ de ácido cítrico para 'Quetzali'. No geral, os resultados estão dentro dos limites reportados por Teixeira et al. (2011) que, encontraram teores médios de acidez variando entre 0.10 ('Pérola') a $0.12 \%$ ('Smile'), coerentes ainda, com o esperado para melancias e dentro dos limites aceitáveis pelo consumidor para comercialização segundo Andrade Júnior et al. (2006).

Houve variação quanto aos valores médios obtidos para a relação SS/AT. A maior relação foi atribuída ao híbrido 'Boston' (86.24), enquanto que a menor relação pode ser verificada no híbrido 'Quetzali' (63.72), tornando evidente que a proporção de açúcar presente no fruto é muito superior em relação à quantidade de ácidos orgânicos presentes, sendo o híbrido considerado mais palatável em relação aos demais. Esta relação fornece indicativo do sabor da fruta, pois relaciona a quantidade de açúcares e ácidos presentes proporcionando boa ideia do equilíbrio entre esses dois componentes.

$\mathrm{O}$ pH enquadrou os híbridos 'Boston' e 'Quetzali' na mesma categoria com valores médios de 5.05 e 5.01 respectivamente. De acordo com Chitarra e Chitarra (2005), a capacidade tampão de alguns sucos permite que ocorram grandes variações na acidez titulável, sem variações apreciáveis no $\mathrm{pH}$. Numa faixa de concentração de ácidos entre 0.5 e $2.5 \%$, o $\mathrm{pH}$ aumenta com o decréscimo da acidez. Vale salientar que os fatores ambientais, além dos de ordem genética, influenciam consideravelmente na composição química dos princípios alimentícios vegetais, onde pode ser esclarecido que a variação na composição química dos frutos deve-se não somente a variedade, mas também ao grau de maturação antes da colheita e as condições de maturação pós-colheita e de armazenagem.

Observou-se variação nos teores médios de açúcares solúveis totais dentre os híbridos avaliados de 5.19 a $6.66 \%$ para os híbridos 'Quetzali' e 'Boston', respectivamente. Este último destacou-se por apresentar melhor sabor doce dentre os híbridos, pois os açúcares solúveis totais são carboidratos de baixo peso molecular, componentes dos sólidos solúveis, responsáveis diretos pela determinação do sabor doce dos frutos (PEREIRA, 2009). Os resultados encontrados são semelhantes aos relatados na literatura por Carlos et al. (2002) que observaram teores de 8.45 a $9.44 \%$ de açúcares solúveis totais em melancia submetida a diferentes temperaturas de armazenamento.

Para açúcares redutores, o híbrido 'Boston' apresentou o maior teor médio (3.16\%), enquanto, que 'Quetzali' apresentou o menor valor (2.90\%). Os resultados mostraram-se condizentes com os estudos realizados em frutos de melancia das cultivares 'Pérola' e 'Crimson Sweet', colhidas na Central de Abastecimento (CEASA) de Goiás e São Paulo, que apresentaram cerca de 4.50 a $4.66 \%$ de açúcares redutores, evidenciando que os híbridos comerciais tipo exportação estudados neste trabalho, 
apresentaram resultados semelhantes aos destinados aos comércios locais do Sudeste e Centro-oeste (DIAS; LIMA, 2010). Vale ressaltar ainda que os principais açúcares presentes em cucurbitáceas são, de forma geral, a glicose e frutose (AR) e a sacarose (ANR). Os açúcares redutores contribuem com quase $100 \%$ do teor de açúcares totais na fase inicial de desenvolvimento dos frutos; todavia, a sacarose pode chegar a até $50 \%$ dos açúcares totais na fase final de maturação, com proporção aproximada de $25 \%$ para glicose e $25 \%$ para frutose (LONG et al., 2004). Os resultados encontrados para pectina solúvel mostram que há diferenças significativas nos teores médios de 16.45 a $17.01 \mathrm{mg}^{100 \mathrm{~g}^{-1}}$ para 'Quetzali' e 'Boston', respectivamente, tendo sido relatados resultados superiores por Miguel et al. (2007) que ao trabalhar com melancia minimamente processada observaram um teor médio de pectina solúvel de $106.20 \mathrm{mg} 100 \mathrm{~g}^{-1}$ no segundo dia de armazenamento.

Os compostos bioativos de frutos de diferentes híbridos de melancia encontram-se na tabela 4 . No contexto genotípico, o híbrido 'Boston' destacou-se por apresentar um teor médio de vitamina $C$ de 7.51 $\mathrm{mg} 100 \mathrm{~g}^{-1}$. Os resultados obtidos mostraram-se condizentes com as contribuições relatadas por Araújo Neto et al. (2010) que ao avaliar qualidade em cinco variedades de melancias em Mossoró-RN obtiveram teores médios de vitamina $\mathrm{C}$ variando entre 6.07 e $8.78 \mathrm{mg} 100 \mathrm{~g}^{-1}$. Quanto aos compostos bioativos, a vitamina $\mathrm{C}$ é dita como um componente nutricionalmente importante e pode ser utilizado como um índice de padrão ou de qualidade de alimentos.
Entretanto, conforme Lee e Kader (2000), o teor de vitamina $C$ pode ser influenciado por vários fatores além das diferenças genotípicas, como condições climáticas, pré-colheita, práticas culturais, grau de maturação, métodos de colheita e manejo póscolheita.

Ao analisar os carotenoides totais, observou-se variação nos teores médios entre os híbridos de 1.18 a $2.03 \mathrm{mg} 100 \mathrm{~g}^{-1}$ para 'Quetzali' e 'Boston', respectivamente, resultados superiores aos preconizados por Fonseca et al. (2010) que analisando teores e tipos de carotenoides em frutos de melancia de polpa vermelha e branca, obtiveram

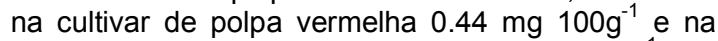
cultivar de polpa branca $0.05 \mathrm{mg} 100 \mathrm{~g}^{-1}$ de carotenóides totais. Deve-se ressaltar que o conteúdo de carotenoides nas frutas e hortaliças depende de vários fatores como: variedade genética, estádio de maturação, armazenamento, processamento e preparo (CAPECKA et al., 2005).

O híbrido 'Boston' apresentou os maiores teores

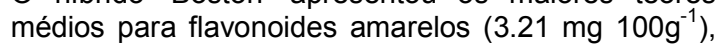
entretanto, o híbrido 'Quetzali', se destacou no conteúdo de antocianinas, apresentando valor médio

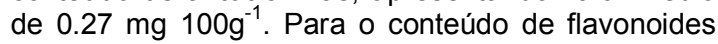
amarelos encontrados os resultados mostraram-se relativamente inferiores quando comparados à frutas como: abacaxi $\left(18,22 \mathrm{mg} 100 \mathrm{~g}^{-1}\right)$ e acerola $(10.73 \mathrm{mg}$ $\left.100 \mathrm{~g}^{-1}\right)$. Todavia, cabe ressaltar que os flavonoides ocorrem naturalmente em frutas frescas e pelo fato de formarem um potente grupo de antioxidantes, fazse necessária a ingestão destes componentes mesmo em pequenas quantidades (RIQUE et al., 2002).

Tabela 3. Características físico-químicas de frutos de diferentes híbridos de melancia nas condições edafoclimáticas dos Estados do Ceará e Rio Grande do Norte. Referencias: Média \pm Desvio padrão; C.V. = Coeficiente de variação. ${ }^{1} \mathrm{SS}=$ Sólidos solúveis; ${ }^{2} A T=$ Acidez titulável; ${ }^{3} \mathrm{SS} / \mathrm{AT}=$ Relação sólidos solúveis/acidez titulável; ${ }^{4} \mathrm{pH}=\mathrm{Potencial}$ hidrogeniônico; ${ }^{5} \mathrm{AST}=$ Açúcar solúvel total; ${ }^{6} \mathrm{AR}=$ Açúcar redutor; ${ }^{7} \mathrm{PEC}=$ Pectina solúvel. Médias seguidas por pelo menos mesma letra nas colunas não diferem entre si, pelo teste de Tukey, ao nível de $5 \%$ de probabilidade.

\begin{tabular}{|c|c|c|c|c|c|c|c|}
\hline \multirow[b]{2}{*}{ Híbridos } & \multicolumn{7}{|c|}{ Características físico-químicas } \\
\hline & $\begin{array}{c}\mathbf{S S}^{\prime} \\
\left({ }^{\circ} \text { Brix }\right)\end{array}$ & $\begin{array}{l}\mathrm{AT}^{2} \\
(\%)\end{array}$ & SS/AT ${ }^{3}$ & $\mathrm{pH}^{4}$ & $\begin{array}{l}\text { AST }^{5} \\
(\%)\end{array}$ & $\begin{array}{l}A R^{6} \\
(\%)\end{array}$ & 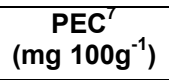 \\
\hline Boston & $9.90 \pm 0.18^{a}$ & $0.11 \pm 0.01^{b}$ & $86.24 \pm 5.06^{a}$ & $5.05 \pm 0.02^{\mathrm{a}}$ & $6.66 \pm 0.85^{\mathrm{a}}$ & $3.16 \pm 0.33^{\mathrm{a}}$ & $17.01 \pm 3.62^{\mathrm{a}}$ \\
\hline Quetzali & $9.28 \pm 0.30^{a}$ & $0.14 \pm 0.01^{a}$ & $63.72 \pm 1.26^{\mathrm{b}}$ & $5.01 \pm 0.09^{a}$ & $5.19 \pm 0.11^{b}$ & $2.90 \pm 0.13^{\mathrm{a}}$ & $16.45 \pm 4.90^{\mathrm{a}}$ \\
\hline Média Geral & 9.59 & 0.13 & 74.98 & 5.03 & 5.93 & 3.03 & 16.73 \\
\hline C.V. (\%) & 2.59 & 6.93 & 4.92 & 1.24 & 10.19 & 8.20 & 25.73 \\
\hline
\end{tabular}

Tabela 4. Compostos bioativos de frutos de diferentes híbridos de melancia cultivados nas condições edafoclimáticas dos Estados do Ceará e Rio Grande do Norte. Referencias: Média \pm Desvio padrão; C.V. = Coeficiente de variação. ${ }^{1} \mathrm{VC}=$ Vitamina $\mathrm{C} ;{ }^{2} \mathrm{CT}=$ Carotenoides totais; ${ }^{3} \mathrm{FA}=$ Flavonoides amarelos; ${ }^{4} \mathrm{ANT}=$ Antocianinas totais; ${ }^{5} \mathrm{LIC}=$ Licopeno; ${ }^{6}$ PET = Polifenóis extraíveis totais. Médias seguidas por pelo menos mesma letra nas colunas não diferem entre si, pelo teste de Tukey, ao nível de $5 \%$ de probabilidade.

\begin{tabular}{|c|c|c|c|c|c|c|}
\hline \multirow[b]{2}{*}{ Híbridos } & \multicolumn{6}{|c|}{ Compostos bioativos } \\
\hline & $\begin{array}{c}V^{1} \\
\left(m g 100 g^{-1}\right)\end{array}$ & $\begin{array}{c}\mathrm{CT}^{2} \\
\left(\mathrm{mg} \mathrm{100 \textrm {g } ^ { - 1 }}\right)\end{array}$ & $\begin{array}{c}F^{3} \\
\left(\mathrm{mg} \mathrm{100g}^{-1}\right)\end{array}$ & $\begin{array}{c}\mathrm{ANT}^{4} \\
\left(\mathrm{mg} \mathrm{100g}^{-1}\right)\end{array}$ & $\begin{array}{c}\text { LIC }^{5} \\
\left(\mathrm{mg} \mathrm{100g}^{-1}\right)\end{array}$ & $\begin{array}{c}\text { PET } \\
\left(\mathrm{mg} \mathrm{100g}^{-1}\right)\end{array}$ \\
\hline Boston & $7.51 \pm 0.27^{\mathrm{a}}$ & $2.03 \pm 0.78^{\mathrm{a}}$ & $3.21 \pm 0.23^{\mathrm{a}}$ & $0.22 \pm 0.03^{\mathrm{a}}$ & $0.65 \pm 0.13^{\mathrm{a}}$ & $97.99 \pm 1.07^{b}$ \\
\hline Quetzali & $6.58 \pm 0.71^{\mathrm{a}}$ & $1.18 \pm 0.27^{\mathrm{a}}$ & $2.63 \pm 0.30^{\mathrm{a}}$ & $0.27 \pm 0.09^{a}$ & $0.58 \pm 0.13^{\mathrm{a}}$ & $194.36 \pm 6.34^{a}$ \\
\hline Média Geral & 7.04 & 1.60 & 2.92 & 0.25 & 0.62 & 146.18 \\
\hline C.V. (\%) & 7.64 & 36.52 & 9.08 & 27.66 & 20.99 & 3.11 \\
\hline
\end{tabular}


Tornando evidente que os teores médios de antocianinas para os híbridos avaliados apresentaram resultados semelhantes à determinadas culturas como: goiaba $\left(0.34 \mathrm{mg} 100 \mathrm{~g}^{-1}\right)$ e mamão $(0.66 \mathrm{mg}$ $100 \mathrm{~g}^{-1}$ ) (BATISTA, 2010). Os vários nuances da cor vermelha das polpas produzidas levam a crer que estão presentes diferentes concentrações de vários tipos de antocianinas (LIMA et al., 2004).

Para licopeno, não houve variação nos teores médios, sendo o maior teor médio obtido para 'Boston' com $0.65 \mathrm{mg} 100 \mathrm{~g}^{-1}$ e o menor para

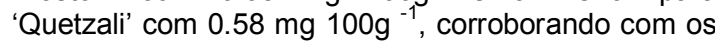
resultados encontrados por Leão et al. (2006) que avaliando oito cultivares de melancia com relação aos teores de licopeno sob condições de produção comercial, obtiveram teores médios variando de 2.22

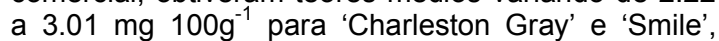
respectivamente. O licopeno é um pigmento de funcionalidade complexa bem abundante em frutas e hortaliças, principalmente presente em frutos de melancia, sendo um composto com excelente atividade de pró-vitamina $\mathrm{A}$ e um dos mais potentes absorvedores de oxigênio singlet entre os carotenoides naturais, funcionando como um antioxidante muito potente.

Houve variação nos teores médios de polifenóis extraíveis totais. 'Quetzali' apresentou um teor médio numericamente mais expressivo, destacando-se positivamente com relação ao híbrido 'Boston' com

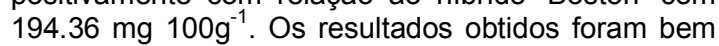
superiores aos encontrados por Aumonde et al. (2011) que analisando enxertia, produção e qualidade de mini melancia 'Smile', encontraram teores de polifenóis extraíveis totais variando entre 21.43 a

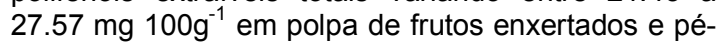
franco, respectivamente.

\section{CONCLUSÕES}

Para as características físicas, observou-se que o híbrido 'Quetzali, apresentou os maiores valores médios para os parâmetros de massa fresca, diâmetros longitudinais e transversais, DL/DT e espessura da casca; entretanto o híbrido 'Boston', apresentou um maior valor médio para a firmeza da polpa.

Quanto à caracterização físico-química, destaque para o híbrido 'Boston' que apresentou maior teor médio de sólidos solúveis, açúcares solúveis totais e SS/AT.

No que diz respeito, aos compostos bioativos, o híbrido 'Boston' apresentou valores médios superiores para carotenoides totais e flavonoides amarelos, enquanto que o híbrido 'Quetzali' destacouse pelo conteúdo de polifenóis extraíveis totais. Os dois híbridos avaliados apresentam compostos funcionais imprescindíveis para a promoção da saúde humana.

Embora tenham se mostrado qualitativamente favoráveis ao consumo, esses resultados indicam estreitamento da base genética para com as variedades avaliadas neste estudo, o que torna necessário a avaliação de outros híbridos.

\section{REFERÊNCIAS BIBLIOGRÁFICAS}

Andrade Júnior, A. S., N. S. Dias, L. G. M. Figueiredo Júnior, V. Q. Ribeiro \& D. B. Sampaio.
2006. Produção e qualidade de frutos de melancia à aplicação de nitrogênio via fertirrigação. Revista Brasileira de Engenharia Agrícola e Ambiental. 10: 836-841.

AOAC. 2000. Official methods of analysis of the association of official analytical chemistry, Washington, 17th Ed. V.2. 777pp.

Araújo Neto, S. E., O. M. Hafle, F. L. Gurgel, J. B. M. Menezes \& G. G. Silva. 2010. Qualidade e vida útil pós-colheita de melancia crimson sweet, comercializada Em Mossoró. Revista Brasileira De Engenharia Agrícola E Ambiental. 4:235-239.

Aumonde, T. Z., N. F. Lopes, R. M. N. Peil, D. M. Moraes, T. Pedó, S. L. C. Prestes \& L. Nora. 2011. Enxertia, produção e qualidade de frutos do híbrido de mini melancia smile. Revista Brasileira de Agrociência, 17:42-50.

Barros, M. M, W.F Araújo, L. T. B. C Neves, A. J Campos \& J. M. Tosin. 2012. Produção E Qualidade DA. MelanciA. SubmetidA. A. Adubação Nitrogenada. Revista Brasileira de Engenharia Agrícola e Ambiental, V: 1078-1084.

Batista, P. F. 2010. Qualidade, compostos bioativos e atividade antioxidante em frutas produzidas no submédio do vale do são francisco. Dissertação (Mestrado Em Agronomia: Fitotecnia) - Universidade Federal Rural Do Semiárido (UFERSA), Mossoró-RN, 162p.

Capecka, E., A. Mareczek \& M. Leja. 2005. Antioxidant activity of fresh and dry herbs of some Lamiaceae especies. Foodchemistry, 93: 223-226.

Carlos, A. L. X., J. B. Menezes, R. H. Rocha, G. H. S. Nunes \& G. G. S. Silva. 2002. Vida útil póscolheita de melancia submetida a diferentes temperaturas de armazenamento. Revista Brasileira de Produtos Agroindustriais, 4: 29-35.

Cavalcante, M. \& M. A. Lira. 2010. Variabilidade genética em Pennisetum Purpureum schumacher. Revista. Caatinga, Mossoró, 23: 153-163.

Chitarra, M. I. \& A. Chitarra. 2005. Pós-colheita de frutos e hortaliças: fisiologia. e manuseio. 2. ED. Lavras: UFLA, 785pp.

Deswal, I. S. \& V. K. Patil. 1984. Effects of $n, p$ and $k$ on the fruit of water melon. Journal of Maharashtra Agricultural Universities, 9: 308-309.

Dias, R. C. S. \& M. A. C. Lima. 2010. Sistemas de produção de melancia. Brasília, Disponível em http://sistemasdeproducao.cnptia.embrapa.br>.

Acesso em: 05 mar. 2014.

FAO. Agricultural Production, Primary Crops. 2011. Disponível Em: <http://www.fao. org>. Acesso Em: 03 marc.

Ferreira, D. F. 2005. Análises estatísticas por meio do sisvar para Windows. Lavras: Universidade Federal de Lavras.

Fonseca, M. E. N., E. D. Silva \& L. S. Boiteux. 2010. Teores e tipos de carotenoides em acessos de melancia com frutos de polpa vermelha e polpa branca. Horticultura. Brasileira, 28: 941-945.

Francis, F. J. 1982. Analysis of anthocyanins. Food ColorS. New York: Academic Press, p.181-207,

Gomes, F. S. 2007. Carotenoides: uma possível proteção contra o desenvolvimento de câncer. Revista de nutrição, 20: 537-548.

Gomes, I. R. 2010. Globalização e novas regiões produtivas no nordeste brasileiro. Mercator - 300 . Revista de Geografia da UFC, 9: 57-74.

Higby, W.K.A. 1962. Simplified method for determination of some the carotenoid distribuition in 
natural and carotene-fortified orange juice. Journal of food science, 27: 42-49.

IAL. 2005. Normas analíticas, métodos químicos e físicos de alimentos. 4. ED. São Paulo: lal.

IBGE. 2006. Sistema. Ibge de recuperação automática. - SIDRA. Disponivel em: $<$ Http://www.ibge. gov. br>. Acesso em: 03 Mar. 2014. Larrauri, J. A., P. Rupérez \& F. Saura-Calixto. 1997. Effect of drying temperature on the stabilitity of polyphenols and antioxidant activity of red grape pomace peels. Journal of Agriculture And Food Chemistry, 45: 1390-1393.

Leão, D. S., J. R. Peixoto \& J. V. Vieira. 2006. Teor de licopeno e de sólidos solúveis totais em oito cultivares de melancia. Bioscl., 22: 7-15.

Lee, S. K. \& A. A. Kader. 2000. Preharvest and postharvest factors influencing vitamin c content of horticultural crops. Postharvest Biology And Technology, 20: 207-220.

Lima, V., E. Melo, M. Maciel, G. Silva \& D. Lima. 2004. Fenólicos totais e atividade antioxidante do extrato aquoso de broto de feijão-mungo (Vigna radiata. L.). Rev. Nutr., 17: 53-57.

Long, R. L., K.B. Walsh, G. Rogers \& D. J. Midmore. 2004. Source sink manipulation to increase melon (Cucumis Melo L.) fruit biomass and soluble sugar content. Australian Journal of Agricultural Research, 55: 1241-1251.

Mcguire, R. G. 1992. Reporting of objective color measurements. Hort Science, 27: 1254-1255,

Mccready, R. M. \& E. A. Mccomb. 1952. Extraction and determination of total pectic materials in fruits. Analyticalchemistry, 24: 1586-1588.

Miguel, A. C. A., J. R. P. S. Dias \& M. H. F. Spoto. 2007. Efeito do cloreto de cálcio na qualidade de melancias minimamente processadas. Horticultura brasileira, 25: 442-446.

Miller, G. L. 1959. Use of dinitrosalicylit acid reagent for determination of reducing sugars. Analytical
Chemistry, 31: 426-428.

Pereira, A. C. S. 2009. Qualidade, compostos bioativos e atividade antioxidante total de frutas tropicais e cítricas produzidas no Ceará. Dissertação (Mestrado). Universidade Federal do Ceará, Fortaleza, 120p.

Perkins-Veazie, P. \& J. K. Collins. 2004. Flesh quality and lycopene stability of flesh-cut watermelon. Postharvest Biology Andtechnolgy, 31:159-166.

Rique, A. B. R., E. Soares \& C. M. Meirelles. 2002. Nutrição e exercício na prevenção e controle das doenças cardiovasculares. Revista Brasideira de Medicina esportiva, 8: 6-8.

Rodriguez-Amaya, D. A. 2001. Guide to carotenoids analysis in food. Washington: International Life Sciences Institute Press, 64p.

Santana, A. F. \& L. F. Oliveira. 2005. Aproveitamento da. Casca de melancia (Cucurbita Citrullus, Shrad) na produção artesanal de doces alternativos. Alimentos e Nutrição, 16: 363-368.

Silva, J. R., G. H. S. Nunes, M. Z. Negreiros \& M. S. M. Torres. 2008. Interação genótipo x ambiente em melancia no estado do Rio Grande do Norte. Revista. Caatinga, 21: 95-100.

Silva, M. L. 2010. Caracterização morfológica e molecular de acessos de melancia. Recife: UFPE, Recife, Dissertação (Mestrado) - Universidade Federal de Pernambuco, 72pp.

Strohecker, R. \& H. M. Henning. 1967. Analisis de vitaminas: métodos comprovados. Paz Montalvo, Madrid. 428p.

Teixeira, F. A., R. C. S. Dias, M. A. Queiroz, L. S. Damaceno \& M. A. C. Lima. 2011. Qualidade físicoquímica. De genótipos de melancia. In: Congresso Brasileiro De Olericultura, 51. ANAIS. Viçosa: Abh.

Yemn, E. W. \& A. J. Willis. 1954. The Estimation Off Carbohydrate In Plant Extracts By Antrone. Biochemical Journal, 57: 504-514. 